\title{
A new treatment for reliable functional and esthetic outcome after local facial flap reconstruction: a transparent polycarbonate facial mask with silicone sheeting
}

\author{
Sander B. Kant ${ }^{1} \cdot$ Patrick I. Ferdinandus ${ }^{1}$ Eric Van den Kerckhove ${ }^{1,2,3}$ • \\ Carlo Colla $^{1}$ - René R. W. J. Van der Hulst ${ }^{1}$ - Andrzej A. Piatkowski de Grzymala ${ }^{1}$ • \\ Stefania M. H. Tuinder ${ }^{1}$
}

Received: 11 January 2017 / Accepted: 29 March 2017 /Published online: 31 May 2017

(C) The Author(s) 2017. This article is an open access publication

\begin{abstract}
Background Facial flap surgery predominantly leads to good functional results. However, in some cases, it can cause unsatisfactory esthetic results. They include persistent erythema, pincushioning, and development of hypertrophic scars. Conservative, reliable treatment for facial flaps is lacking. Pressure and silicone therapy have proven to result in significant improvement in scar erythema, pliability, and thickness in postburn hypertrophic scars. By combining these therapies in a facial mask, the esthetic outcome of facial flaps could be improved. In this retrospective study, the efficacy of a unique transparent face mask containing silicone sheets on the esthetic outcome of postsurgical facial flaps is assessed.

Methods Twenty-one patients were assigned to facial pressure mask therapy after they underwent facial flap surgery between July 2012 and September 2015. Patients were treated for a mean duration of 46 weeks. The effects of pressure mask therapy were examined by means of the Patient and Observer Scar Assessment Scale (POSAS).
\end{abstract}

Sander B. Kant

sanderkant1@gmail.com

1 Department of Plastic Surgery, Maastricht University Medical Center, P Debyelaan 25, 6229HX Maastricht, The Netherlands

2 KU Leuven, Department of Rehabilitation Sciences, Faber, Universitaire Ziekenhuizen Leuven, Leuven, Belgium

3 Department of Physical Medicine and Rehabilitation and Burns Center, Universitaire Ziekenhuizen Leuven, Leuven, Belgium
Results All POSAS components showed a reduction between start and end of therapy, while itchiness, pigmentation, pliability, thickness, and relief of the flap improved significantly $(P<0.05)$. Mean total and patient score showed significant reduction between start and end of therapy.

Conclusions This study shows that a facial pressure mask layered with silicone results in noticeable flap improvement with a long-lasting result.

Level of Evidence: Level III, therapeutic study.

Keywords Facial flap reconstruction · Pressure mask . Silicones

\section{Introduction}

Worldwide, the number of people that suffer from skin cancer is increasing every year. Surgical resection is the standard of care in facial plastic surgery [1]. One of the standard procedures to close facial defects is local or regional soft tissue flaps [2].

In order to cover a defect and to restore facial anatomy as well as possible, many options for surgical flaps exist. Well-known and commonly used flaps include Abbe, rhomboid, forehead, bilobed, and glabella flap [3, 4]. All of these flaps are known to mostly give good esthetic results. However, esthetic outcome may not be satisfying in all cases. Most adverse effects after repair of defects in the face by flaps are mild. They include persistent scar erythema, pincushioning, and development of hypertrophic and widened scars [1, 5-11].

Current therapies for flap revision after unsatisfactory esthetic results include photothermolysis, laser resurfacing, 
liposuction, injections with corticosteroids, and surgery $[1,8$, $10,12]$. These treatment modalities are invasive, while studies evaluating long-term efficacy of these methods on flaps are lacking. Reliable conservative therapy with long-term stable result is the hiatus in current clinical practice.

Two non-surgical procedures that have been the cornerstone in treatment for hypertrophic and keloid scars for many years are pressure garment therapy and therapy with silicones [13-16].

We hypothesize that combination therapy of silicones and pressure could lead to reducing edema and rigidity as well as cause flattening of the facial flap, as an effect of applying mechanical pressure. Additionally, combination therapy could have scar enhancing and maturation accelerating properties, as effects of both silicones and pressure. In this way, silicone and pressure therapy could act in synergetic fashion to improve esthetic outcome of thickened facial flaps with unsatisfying scars.

In order to incorporate pressure and silicone therapy, we believe that a specialized pressure mask with a silicone layer as inner lining can improve pliability and color and reduce thickness, edema, and irregularities of flaps exposing these qualities. In this study, the efficacy of a unique transparent face mask containing silicone sheets on the esthetic outcome of postsurgical facial flaps is assessed.

\section{Materials and methods}

\section{Design}

In this retrospective study conducted between July 2012 and September 2015, 21 patients were assigned to facial pressure mask therapy with silicones after they underwent flap surgery. Patient characteristics and follow-up information can be seen in Table 1 .

In order to improve the facial skin functionally and esthetically at the autologous transplantation site (the flap) after surgery, treatment with a transparent polycarbonate facial pressure mask with a silicone layer as inner lining was applied. The different types of surgical flaps used and the reason for surgery are documented in Tables 2 and 3, respectively.

\section{Patients}

Eligible patients were men or women who had received facial flap surgery. Only patients in whom the flap clearly protruded from the normal skin, even after thinning of the
Table 1 Patient characteristics

\begin{tabular}{lr} 
Age at start therapy (years) & \\
$<40$ & 2 \\
$40-49$ & 3 \\
$50-59$ & 5 \\
$>60$ & 11 \\
Mean age (years) & 57 \\
Min & 34 \\
Max & 80 \\
Gender & \\
Male & 9 \\
Female & 12 \\
Follow-up time (weeks) & \\
$10-20$ & 5 \\
$20-40$ & 6 \\
$40-60$ & 3 \\
$60-80$ & 3 \\
$80-100$ & 3 \\
$>100$ & 1 \\
Mean duration of treatment & 46 \\
(weeks) & 11 \\
Min & \\
Max & \\
\hline
\end{tabular}

flap, were included. Only patients that did not receive any prior therapy for their facial flap were included. If these patients were physically and mentally able and motivated to wear a polycarbonate facial pressure mask for at least $12 \mathrm{~h}$ a day, they were suitable and assigned for facial mask therapy. Therapy started when the operated skin passed into the maturation phase of wound healing. Therefore, therapy started between 1 and 3 months after flap surgery took place. The study conformed to good clinical practice guidelines and followed the recommendations of the Declaration of Helsinki. The protocol was approved by the local ethics committee.

Table 2 Surgical flaps used

\begin{tabular}{ll}
\hline & No. \\
\hline Abbe flap & 1 \\
Bilobed flap & 3 \\
Forehead flap & 7 \\
Glabella flap & 2 \\
Limberg flap & 1 \\
Transposition flap & 3 \\
Rotation flap & 1 \\
Z-plasty & 3 \\
\hline
\end{tabular}


Table 3 Reason for flap surgery

\begin{tabular}{lc}
\hline & No. \\
\hline Reconstruction of the face after removal of \\
Basal cell carcinoma & 13 \\
Melanoma & 2 \\
Radical scar excision & 3 \\
Sarcoma & 1 \\
Squamous cell carcinoma & 2 \\
\hline
\end{tabular}

\section{Procedures}

From July 2012 to September 2015, 21 patients were assigned to therapy with a transparent polycarbonate facial mask with a silicone layer inside. The mask was fully custom fabricated by an experienced prosthetist.

In order to apply the required pressure to the flap underneath the mask, Velcro straps were attached to the polycarbonate outside of the mask. Targeted pressure was $20 \mathrm{mmHg}$. Pressure under the mask was measured by means of an aerial pressure sensor and pump.

Patients were advised and insisted to wear the mask as long as they possibly could endure, with the objective to wear the mask at least $12 \mathrm{~h}$ every day. When an adequate and satisfying esthetic result was reached, patient and doctor mutually decided to stop therapy. Compliance was evaluated, and if patients were incompliant, mask therapy was stopped. Therapy was also stopped if patients reported a high level of discomfort. All included patients of the current study completed the therapy. The mean duration of the therapy was 46 (11112) weeks. During this period, patients returned for follow-up every 3 to 4 months at the outpatient clinic. The flaps were assessed at the scar clinic by a team of experts in scar treatment and management including a senior plastic surgeon, a resident plastic surgeon, a prosthetist, and a physiotherapist. At each visit, POSAS forms were filled out, and photographs were taken. Facial mask pressure was monitored on each visit, and when necessary, adjustments of the mask were performed by the prosthetist.

\section{Assessment of flap}

Because no objective and validated tool for assessment of thickened facial flaps exists, we used the previously validated Patient and Observer Scar Assessment Scale (POSAS) for evaluating facial skin and scars at the transposition site [17]. At most 2 weeks prior to fabrication of the mask, the facial skin and scars were first assessed. The flap was rated numerically on a 10-step scale by both the patient and doctor on six items. The Observer Scale rates vascularity, pigmentation, thickness, relief, pliability, and surface area. The Patient Scale consists of pain, itchiness, color, pliability, thickness, and relief. Patients were informed to assess the facial reconstruction as a whole (both flap and scar together) not solely the scar, on the six components of the Patient Scale.

One of the reasons POSAS was chosen for flap evaluation is because it is the only scar assessment tool to include a component for patients to fill out. Furthermore, we chose POSAS because of its distinctive feature of reflecting subjective symptoms like pain and itchiness and because of its usefulness for everyday practice [18-20].

On each visit, an expert and the patient independently filled in a POSAS form in order to assess the transposition site.

\section{Data analysis}

POSAS scores are presented as means with standard deviations. Those scores were compared with the use of one-way ANOVA for significance in means. Twotailed values of $P<0.05$ were accepted as statistically significant. All analyses were performed using the statistical software program SPSS 22.0.

\section{Results}

\section{Outcome mean patient, observer, and total POSAS score}

All flap sites were evaluated prior to or on the day the mask therapy started by means of POSAS scores. POSAS scores at baseline and at the end of therapy were compared by means of one-way ANOVA.

Figure 1 and Table 4 show that mean POSAS scores decreased significantly $(P<0.05)$ between baseline and end of therapy, with a total of 18.72 points.

Patient scores also decreased significantly $(P<0.05)$ with a mean total of 14.81 points, between baseline and end of therapy (Table 5).

Observer scores showed a mean reduction of 3.90 points between baseline and end of therapy. However, this reduction was not statistically significant (Table 6). 
Fig. 1 Mean patient, observer, and total POSAS scores are shown at baseline and end of therapy. Statistically significant differences $(P<0.05)$ between means are marked by an asterisk

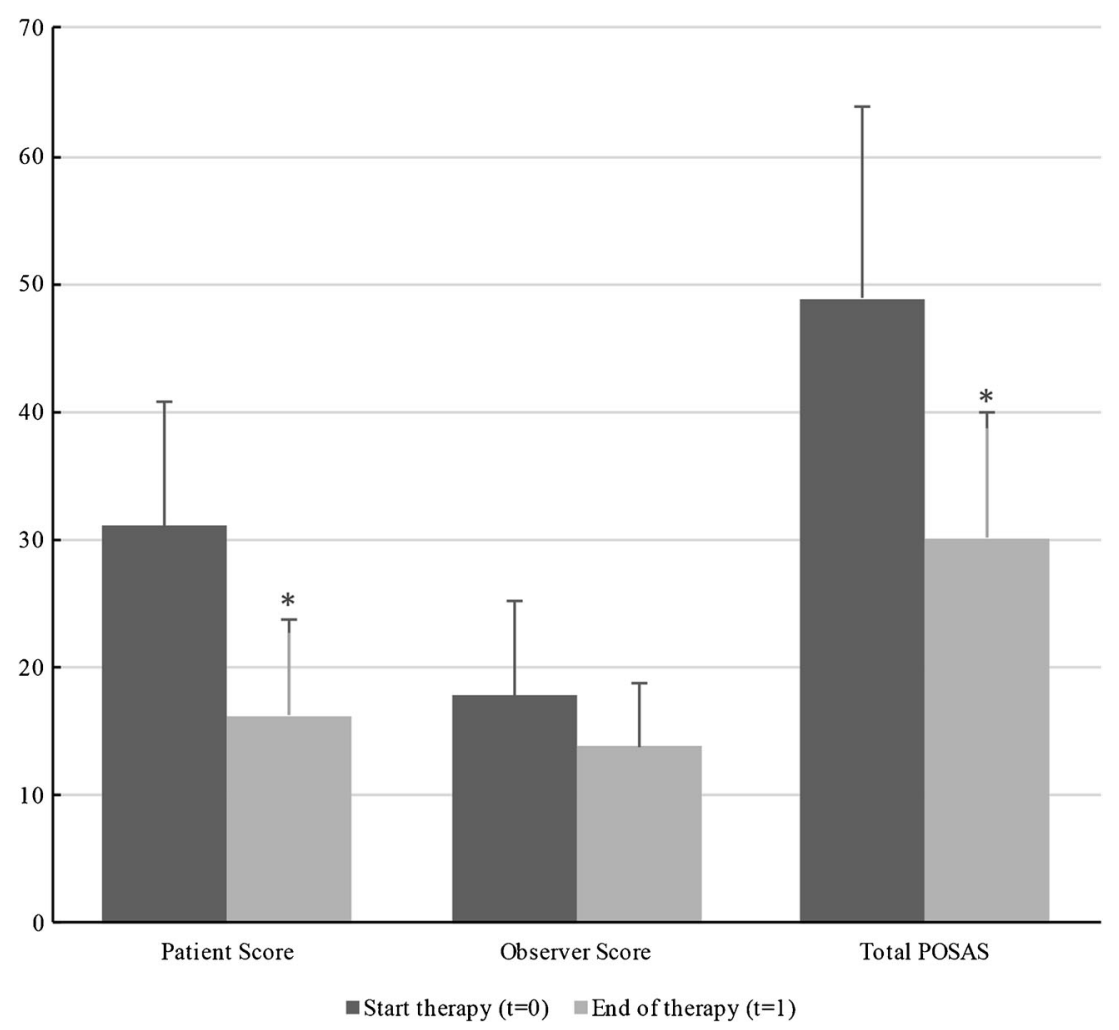

Start therapy $(\mathrm{t}=0) \quad \square$ End of therapy $(\mathrm{t}=1)$

and relief showed a statistically significant reduction $(P<0.05)$ between baseline and end of therapy.

\section{Observer scores}

Table 6 and Fig. 3 show the six characteristics of the observer score (vascularization, pigmentation, thickness, relief, pliability, and surface area) at start and end of

Table 5 Mean patient scar scores

Overall patient score

\begin{tabular}{lccccc}
\hline & Start therapy & SD & End of therapy & SD & $P$ value \\
\hline Pain & 2.48 & 2.21 & 1.38 & 1.32 & 0.060 \\
Itchiness & 3.62 & 2.42 & 2.10 & 1.81 & 0.026 \\
Pigmentation & 5.67 & 2.99 & 3.67 & 1.74 & 0.012 \\
Pliability & 5.90 & 2.64 & 2.86 & 2.01 & $<0.001$ \\
Thickness & 6.81 & 1.81 & 2.86 & 2.01 & $<0.001$ \\
Relief & 6.67 & 2.13 & 3.43 & 2.04 & $<0.001$ \\
Patient score & 31.10 & 9.76 & 16.29 & 7.43 & $<0.001$ \\
\hline
\end{tabular}


Table 6 Mean observer scar scores

Overall observer score

\begin{tabular}{lccccc}
\hline & $\begin{array}{l}\text { Start } \\
\text { therapy }\end{array}$ & SD & $\begin{array}{l}\text { End of } \\
\text { therapy }\end{array}$ & SD & $P$ value \\
\hline Vascularization & 3.62 & 1.88 & 3.00 & 1.55 & 0.252 \\
Pigmentation & 2.14 & 1.42 & 2.00 & 1.05 & 0.713 \\
Thickness & 3.38 & 1.40 & 2.19 & 1.08 & 0.004 \\
Relief & 3.48 & 1.20 & 2.67 & 1.16 & 0.035 \\
Pliability & 2.95 & 1.43 & 1.90 & 1.09 & 0.011 \\
Surface area & 2.57 & 1.63 & 1.95 & 0.87 & 0.132 \\
Observer score & 17.76 & 7.38 & 13.86 & 4.99 & 0.051 \\
\hline
\end{tabular}

therapy. Corresponding to the patient scores, all components of the observer score decreased after start of therapy. The largest decrease in observer score was seen in flap thickness, with a mean reduction of 1.19 points between baseline and end of therapy. Pliability, thickness, and relief were the observer score components that showed statistically significant reduction $(P<0.05)$.
Representative cases are depicted in Figs. 4, 5, 6, 7, $8,9,10$, and 11 .

\section{Discussion}

\section{Pressure therapy}

Mechanical compression by means of pressure garment therapy is a reputable modality to diminish collagen synthesis by reducing blood flow. Another hypothesis for the action of pressure therapy is a decrease in blood flow that causes hypoxia, resulting in fibroblast degeneration and loosening of collagen fibrils $[21,22]$. Pressure garment therapy has also proven to result in significant improvement in scar erythema and thickness in postburn hypertrophic scars [23].

Since the 1980s roughly, various types of facial topical therapies have been described [24, 25]. The transparent face mask or transparent face orthosis is a well-known and effective modality in the management of burn-related hypertrophic scars, as it has proven to reduce hypertrophic scars significantly [26]. For the fabrication process of the mask, different
Fig. 2 Components of the patient score as part of the total POSAS score are displayed at start and end of therapy. Statistically significant differences $(P<0.05)$ between means are marked by an asterisk

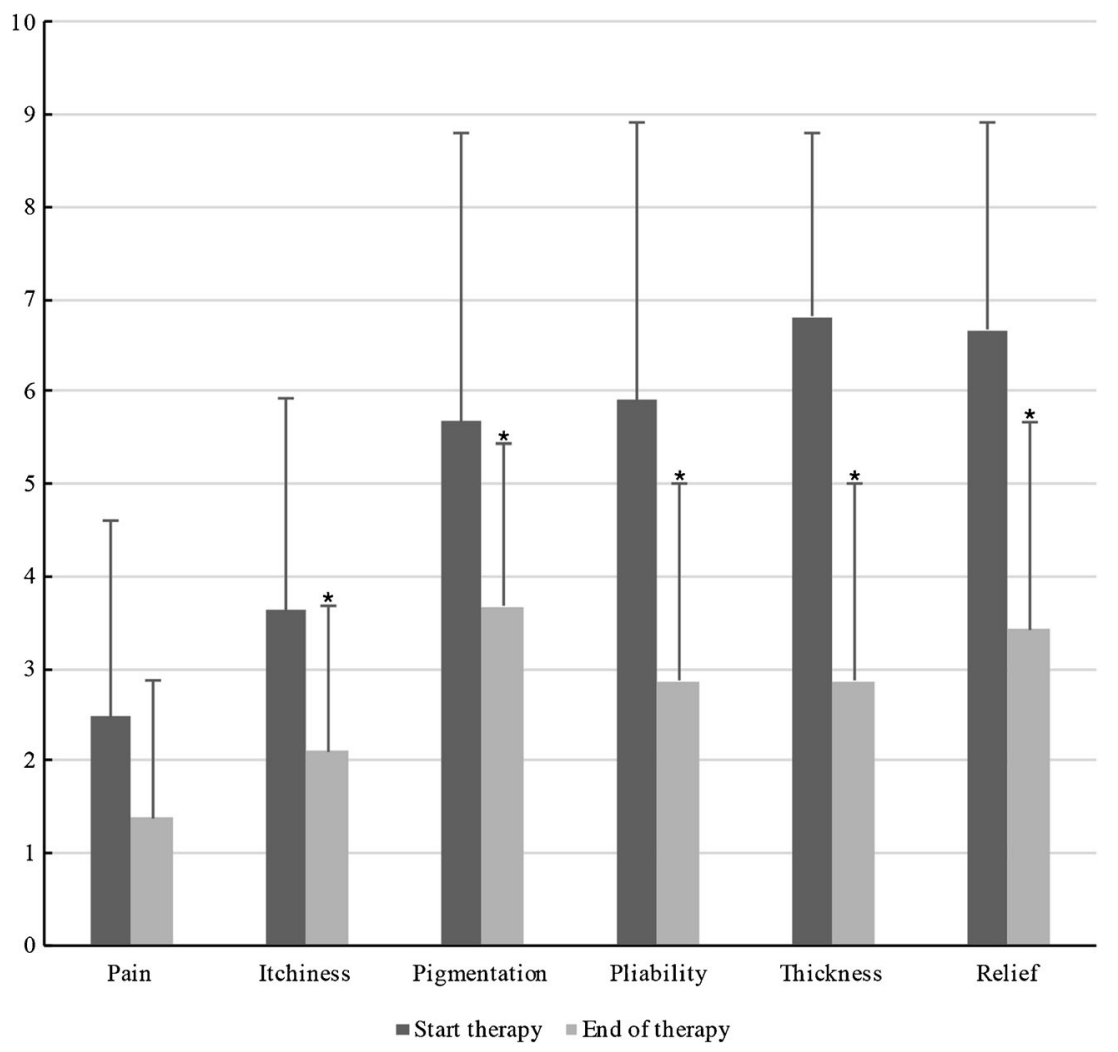


Fig. 3 Components of the observer score as part of the total POSAS score are displayed at start and end of therapy. Statistically significant differences $(P<0.05)$ between means are marked by an asterisk

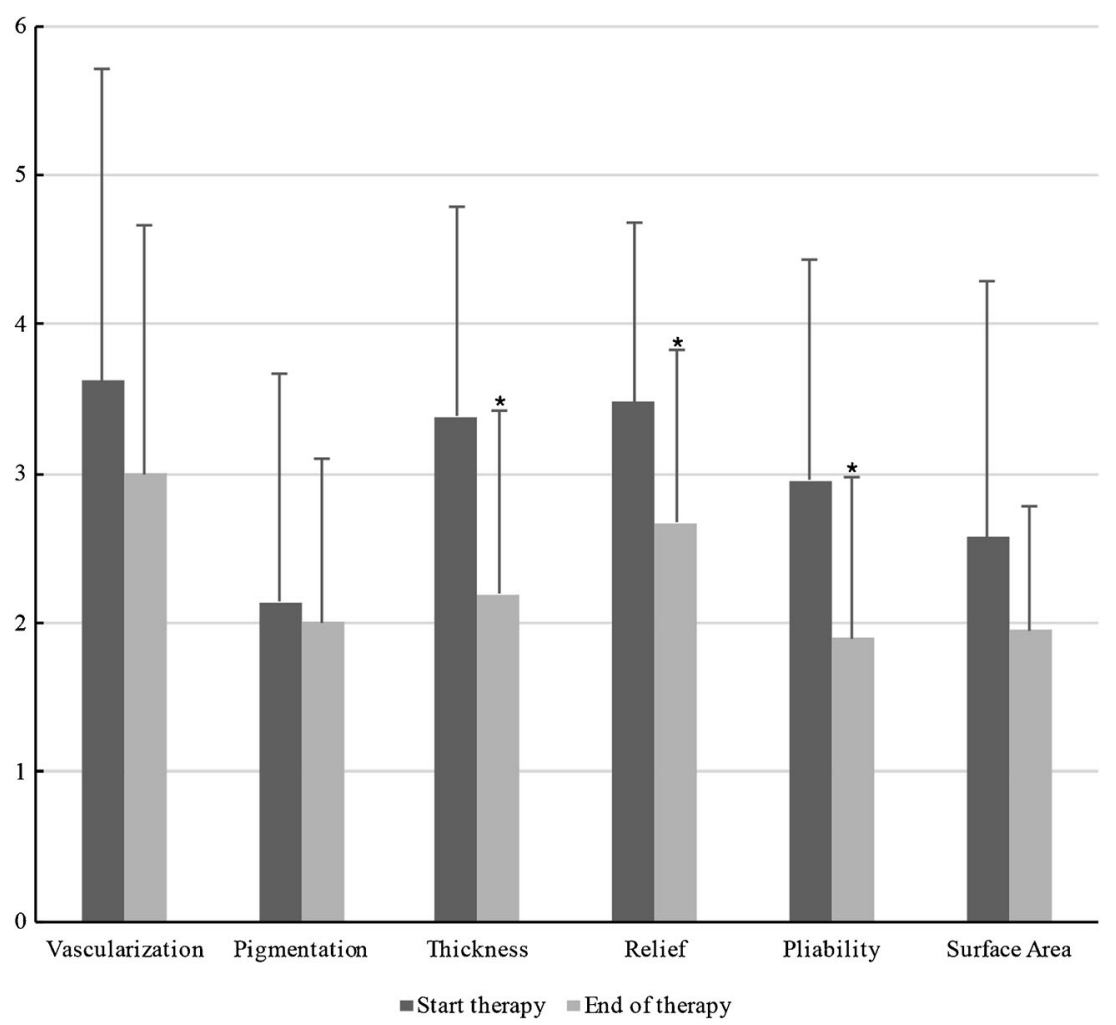

techniques exist, among the formation of both manual and laser-generated molds [24, 27].

When pressure therapy is applied to flaps in extremities, it reduces edema, and it helps to reconstruct and reshape a defect after flap surgery [28]. Further evidence for pressure therapy in reshaping and correcting flaps can mainly be addressed as anecdotal.

\section{Silicone therapy}

Silicone therapy for scars has become standard practice among plastic surgeons, as there is good clinical evidence of the efficacy $[29,30]$. One of the mechanisms to occur after application of silicones to the skin is an increase of hydration. As an effect of increased hydration, capillary activity could decrease, thereby reducing local collagen deposition [31]. The clinical effects of increased hydration include improvement of pruritus, pain, pliability, and decrease of edema [32, 33].

\section{Combination therapy}

However, the combined effect of pressure therapy and silicones is less studied. A randomized controlled trial (RCT) demonstrated that silicones combined with pressure therapy were associated with significant improvement in pliability, thickness, and vascularity of 38 hypertrophic burn scars [34]. A smaller pilot RCT showed inconclusive evidence on the potential beneficial effect of combination therapy on 30 hypertrophic burn scars [35]. A larger RCT demonstrated combined therapy to be effective in improving thickness of hypertrophic postburn scars, compared to silicone and pressure therapy separately [36].

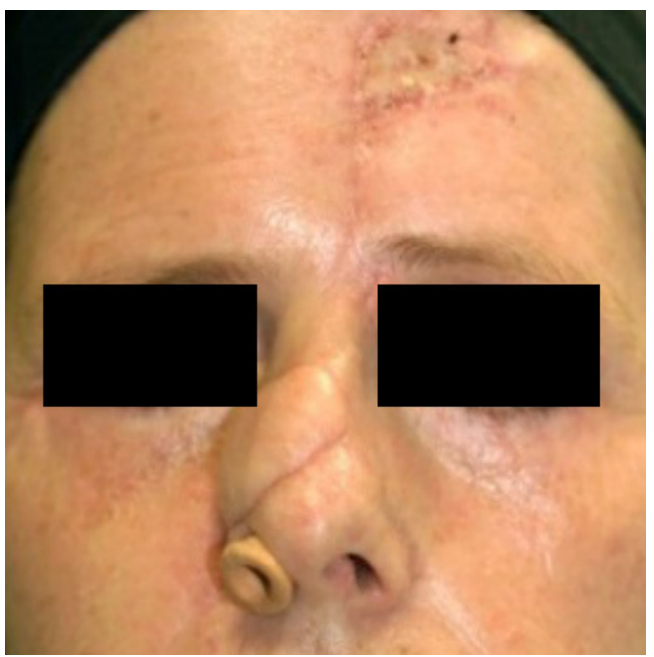

Fig. 4 A 50-year old female patient at the start of pressure mask therapy 4 months after surgery 


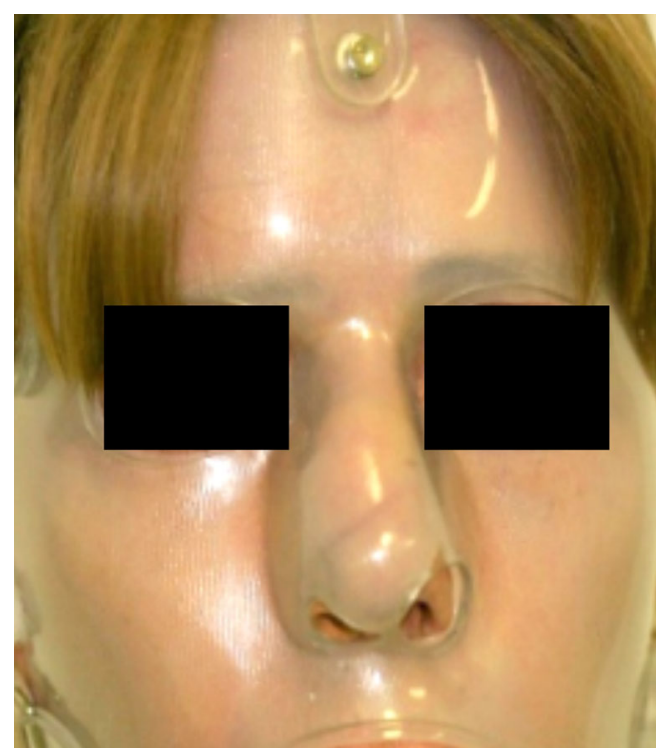

Fig. 5 Same female patient with pressure mask applied during therapy

In this study, we have shown that specialized facial mask therapy significantly improves esthetic outcome after facial flap surgery. Mean total POSAS scores showed a significant decrease between baseline and end of therapy (Table 4, Fig. 1), with mean therapy duration of 46 weeks (Table 1).

Our results show patients' opinion about their facial reconstruction improved the most, with a significant improvement $(P<0.05)$ in itchiness, pliability, pigmentation, thickness, and relief (Table 5, Fig. 2).

Overall, observer POSAS scores did not show significant reduction over time $(P=0.051)$. However, thickness, relief, and pliability, as part of the observer score, did reduce significantly (Table 6).

To our knowledge, extensive and long-term studies about esthetic outcome after facial flap surgery are lacking. Also, the effect of a facial pressure mask for improvement in esthetic

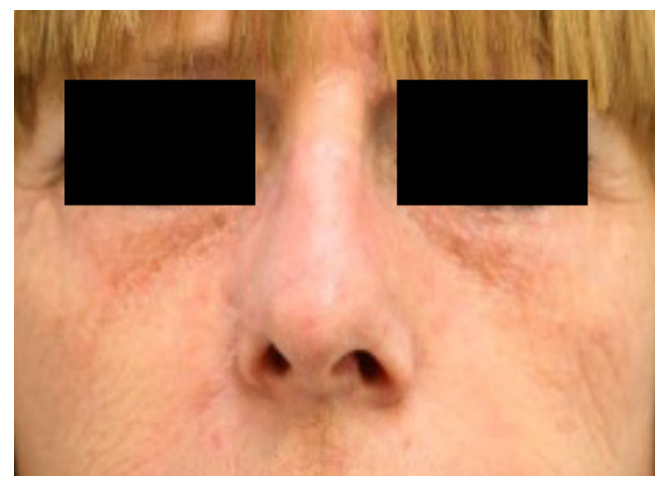

Fig. 6 Same female patient at the end of pressure mask therapy 9 months after surgery

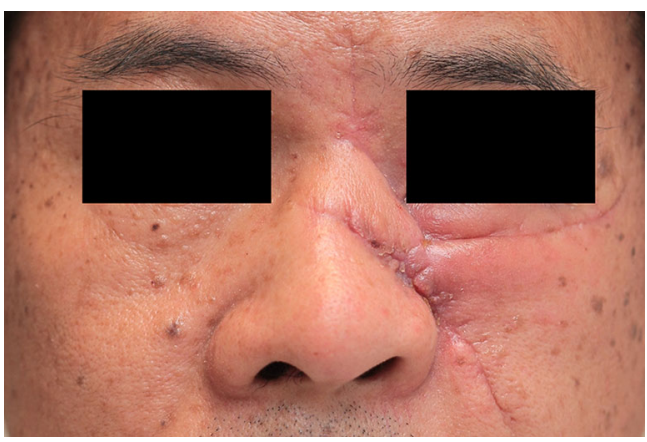

Fig. 7 A 48 year-old male patient at the start of pressure mask therapy 3 months after surgery (frontal view)

outcome for flaps has not been documented earlier. A limited amount of methods for esthetic refinement after flap surgery is available in current clinical practice. Yet, intraoperative intradermal injections of methylprednisolone can reduce flap edema, according to an animal study [37]. Other methods for esthetic refinements after facial flap surgery include photothermolysis and laser resurfacing.

In accordance with our results, we believe that our specialized pressure mask could be an effective modality to avoid surgical debulking or thinning of flaps, with small risk of complications and adverse effects in contrast to surgery.

\section{Strengths and limitations}

This is the first clinical cohort study to assess the usefulness of a facial pressure mask with silicones for enhancement after facial flap surgery. There were some limitations of this study. In the absence of a flap assessment scale, the validated and well-known clinical scar assessment tool POSAS is the only

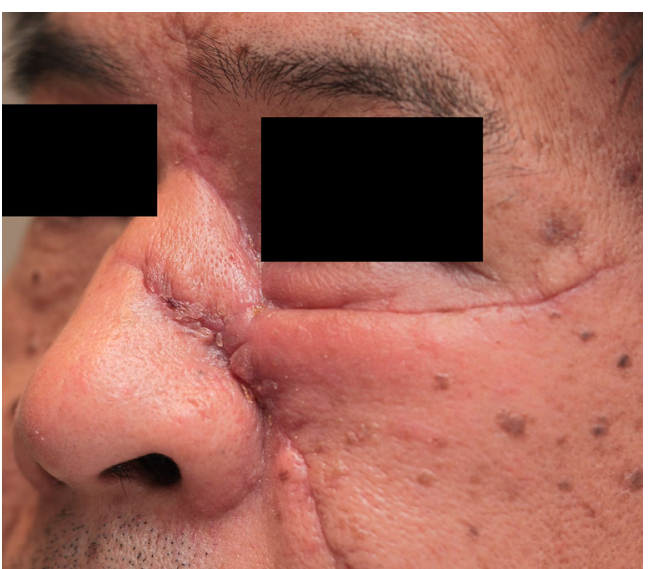

Fig. 8 A 48 year-old male patient at the start of pressure mask therapy 3 months after surgery (oblique view) 


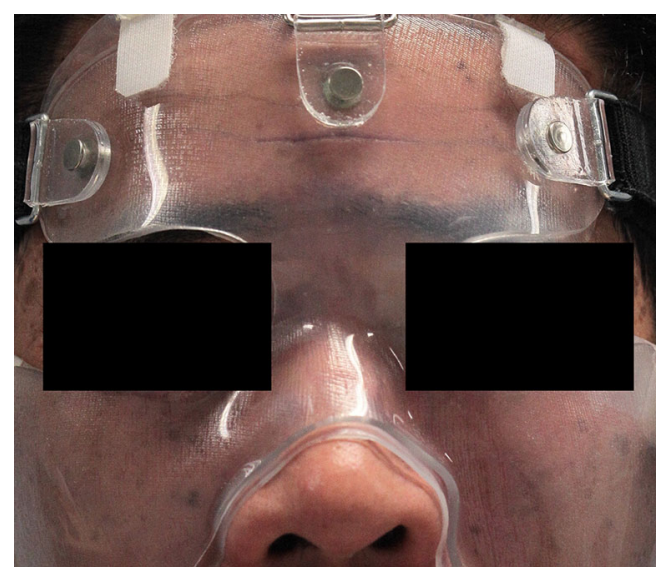

Fig. 9 Same patient with pressure mask applied during therapy

instrument for flap assessment used in this study. Other qualitative methods for judging flaps are lacking in this study. Preferably, the current study would contain a larger study population and a control group. However, the vast majority of patients appear to have good esthetic results after facial flap surgery, causing the remaining eligible patient group to be of small size. Additionally, the burden of wearing a pressure mask for at least $12 \mathrm{~h}$ a day should not be underestimated. The strength of this study is that it shows clearly that patients who wore a pressure mask had strong esthetical improvement of the facial reconstruction site.

\section{Further research}

In order to assess esthetic outcomes after flap reconstruction, more extensive and precise, 3D digital flap volume measurements, as well as continuous pressure measurements underneath the mask, would be of great value. Ideally, further studies would contain a control group, considering that

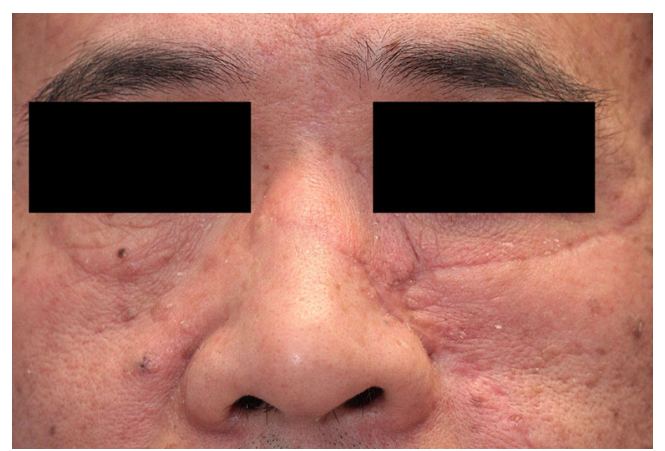

Fig. 10 Same male patient at the end of pressure mask therapy 15 months after surgery (frontal view)

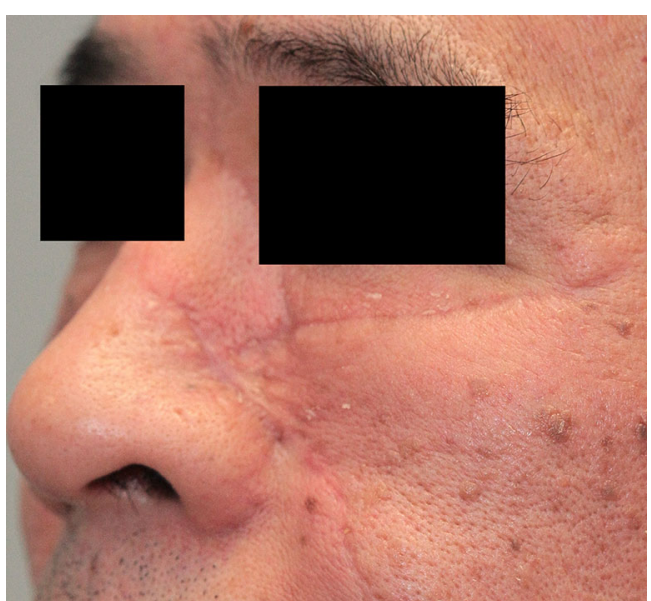

Fig. 11 Same male patient at the end of pressure mask therapy 15 months after surgery (oblique view)

information about the natural course of thickened, hypertrophic, and unesthetic facial flaps over time is lacking.

A major goal of this study was the improvement in overall esthetic outcome: restoration of flap skin close to normal skin. In this study, patients showed a clinical significant result in esthetic improvement of facial flaps.

\section{Conclusion}

In this study, our aim was to assess the efficacy of a specialized facial pressure mask on the esthetic outcome of facial flaps, since no other study examined the effect of facial pressure therapy with silicones on flap enhancement over a reasonable amount of time. Our retrospective study showed that a transparent facial pressure mask with silicones results in noticeable flap improvement with a long-lasting result, particularly in our patients' view.

\section{Compliance with ethical standards}

Conflict of interest Sander B. Kant, Patrick I. Ferdinandus, Eric Van den Kerckhove, Carlo Colla, René R. W. J. Van der Hulst, Andrzej A. Piatkowski de Grzymala, and Stefania M. H. Tuinder declare that they have no conflict of interest.

Ethical approval All procedures performed in studies involving human participants were in accordance with the ethical standards of the institutional and/or national research committee and with the 1964 Helsinki Declaration and its later amendments or comparable ethical standards. 
Patient consent Patients provided written consent before their inclusion in this study. Additional consent was obtained for the use of their images.

\section{Funding None.}

Open Access This article is distributed under the terms of the Creative Commons Attribution 4.0 International License (http:// creativecommons.org/licenses/by/4.0/), which permits unrestricted use, distribution, and reproduction in any medium, provided you give appropriate credit to the original author(s) and the source, provide a link to the Creative Commons license, and indicate if changes were made.

\section{References}

1. Sclafani AP, Sclafani JA, Sclafani AM (2012) Successes, revisions, and postoperative complications in 446 Mohs defect repairs. Facial Plast Surg 28:358-366

2. Lewin JM, Carucci JA (2015) Advances in the management of basal cell carcinoma. F1000Prime Rep 7:53

3. Clark JM, Wang TD (2001) Local flaps in scar revision. Facial Plast Surg 17:295-308

4. Garg S, Dahiya N, Gupta S (2014) Surgical scar revision: an overview. J Cutan Aesthet Surg 7:3-13

5. Collins J, Ayeni O, Thoma A (2012) A systematic review of anterolateral thigh flap donor site morbidity. Can J Plast Surg 20:1723

6. Menick FJ (2007) Defects of the nose, lip, and cheek: rebuilding the composite defect. Plast Reconstr Surg 120:887898

7. Park SS (2013) Revisiting the single-stage forehead flap in nasal reconstruction. JAMA Facial Plast Surg 15:383-384

8. Pawar SS, Kim MM (2013) Updates in forehead flap reconstruction of facial defects. Curr Opin Otolaryngol Head Neck Surg 21:384 388

9. Woodard CR (2013) Complications in facial flap surgery. Facial Plast Surg Clin North Am 21:599-604

10. Yong JS, Christophel JJ, Park SS (2014) Repair of intermediate-size nasal defects: a working algorithm. JAMA Otolaryngol Head Neck Surg 140:1027-1033

11. Zoumalan RA, Murakami CS (2012) Facial flap complications. Facial Plast Surg 28:347-353

12. Huang SH, Wu SH, Chang KP et al (2009) Contour refinements of free flaps for optimal outcome in oral reconstruction: combination of modified liposuction technique and wplasty in one-stage procedure. J Craniomaxillofac Surg 37: 201-205

13. Linares HA, Larson DL, Willis-Galstaun BA (1993) Historical notes on the use of pressure in the treatment of hypertrophic scars or keloids. Burns 19:17-21

14. Lyle WG (2001) Silicone gel sheeting. Plast Reconstr Surg 107: 272-275

15. Monstrey S, Middelkoop E, Vranckx JJ et al (2014) Updated scar management practical guidelines: non-invasive and invasive measures. J Plast Reconstr Aesthet Surg 67:10171025

16. Sharp PA, Pan B, Yakuboff KP, Rothchild D (2016) Development of a Best Evidence Statement for the Use of
Pressure Therapy for Management of Hypertrophic Scarring. J Burn Care Res 37(4):255-64

17. Draaijers LJ, Tempelman FR, Botman YA et al (2004) The patient and observer scar assessment scale: a reliable and feasible tool for scar evaluation. Plast Reconstr Surg 113: 1960-1965

18. Fearmonti RM, Bond JE, Erdmann D, Levin LS, Pizzo SV, Levinson H (2011) The modified Patient and Observer Scar Assessment Scale: a novel approach to defining pathologic and nonpathologic scarring. Plast Reconstr Surg 127:242247

19. Roques C, Teot L (2007) A critical analysis of measurements used to assess and manage scars. Int $\mathrm{J}$ Low Extrem Wounds 6:249-253

20. Stavrou D, Haik J, Weissman O, Goldan O, Tessone A, Winkler E (2009) Patient and observer scar assessment scale: how good is it? J Wound Care 18:171-176

21. Brissett AE, Sherris DA (2001) Scar contractures, hypertrophic scars, and keloids. Facial Plast Surg 17:263-272

22. Chang LW, Deng WP, Yeong EK, Wu CY, Yeh SW (2008) Pressure effects on the growth of human scar fibroblasts. J Burn Care Res 29: $835-841$

23. Van den Kerckhove E, Stappaerts K, Fieuws S et al (2005) The assessment of erythema and thickness on burn related scars during pressure garment therapy as a preventive measure for hypertrophic scarring. Burns 31:696-702

24. Parry I, Hanley C, Niszczak J, Sen S, Palmieri T, Greenhalgh D (2013) Harnessing the transparent face orthosis for facial scar management: a comparison of methods. Burns 39:950-956

25. Leon-Villapalos J, Jeschke MG, Herndon DN (2008) Topical management of facial burns. Burns 34:903-911

26. Anzarut A, Olson J, Singh P, Rowe BH, Tredget EE (2009) The effectiveness of pressure garment therapy for the prevention of abnormal scarring after burn injury: a meta-analysis. J Plast Reconstr Aesthet Surg 62:77-84

27. Wei Y, Li-Tsang CW, Liu J, Xie L, Yue S (2016) 3D-printed transparent facemasks in the treatment of facial hypertrophic scars of young children with burns. Burns

28. West SF, Pidcoe PE (2008) Rehabilitation following surgery for reconstruction of a foot defect. Clin Med Case Rep 1:311

29. Signorini M, Clementoni MT (2007) Clinical evaluation of a new self-drying silicone gel in the treatment of scars: a preliminary report. Aesthet Plast Surg 31:183-187

30. Rabello FB, Souza CD, Farina JA Jr (2014) Update on hypertrophic scar treatment. Clinics 69:565-573

31. Berman B, Perez OA, Konda S et al (2007) A review of the biologic effects, clinical efficacy, and safety of silicone elastomer sheeting for hypertrophic and keloid scar treatment and management. Dermatol Surg 33:1291-1302

32. Phillips TJ, Gerstein AD, Lordan V (1996) A randomized controlled trial of hydrocolloid dressing in the treatment of hypertrophic scars and keloids. Dermatol Surg 22:775-778

33. Quinn KJ, Evans JH, Courtney JM, Gaylor JD, Reid WH (1985) Non-pressure treatment of hypertrophic scars. Burns Incl Therm Inj 12:102-108

34. Steinstraesser L, Flak E, Witte B et al (2011) Pressure garment therapy alone and in combination with silicone for the prevention of hypertrophic scarring: randomized controlled trial with intraindividual comparison. Plast Reconstr Surg $128: 306 \mathrm{e}-313 \mathrm{e}$ 
35. Harte D, Gordon J, Shaw M, Stinson M, Porter-Armstrong A (2009) The use of pressure and silicone in hypertrophic scar management in burns patients: a pilot randomized controlled trial. $\mathrm{J}$ Burn Care Res 30:632-642

36. Li-Tsang CW, Zheng YP, Lau JC (2010) A randomized clinical trial to study the effect of silicone gel dressing and pressure therapy on posttraumatic hypertrophic scars. J Burn Care Res 31:448-457

37. Schmidt JH, Caffee HH (1990) The efficacy of methylprednisolone in reducing flap edema. Plast Reconstr Surg 86: $1148-1151$ 